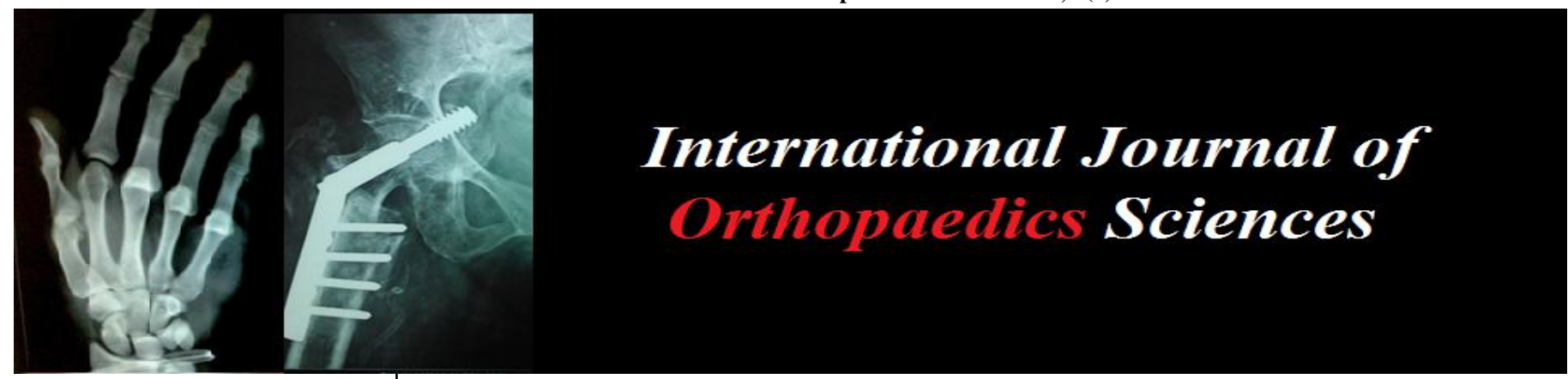

ISSN: $2395-1958$

IJOS 2018; 4(4): 510-514

(C) 2018 IJOS

www.orthopaper.com

Received: 19-08-2018

Accepted: 20-09-2018

Dr. Siddharth D Parekh Lokmanya Tilak Municipal Medical College, Mumbai,

Maharashtra, India

Dr. Arvind B Goregaonkar Professor and Head, Department of Orthopaedics, Lokmanya Tilak Municipal Medical College, Mumbai, Maharashtra, India

Dr. Anoop Dhamangaokar Lokmanya Tilak Municipal Medical College, Mumbai,

Maharashtra, India

Dr. Apratim R Deekshit Lokmanya Tilak Municipal Medical College, Mumbai, Maharashtra, India

Dr. Umesh P Kanade Lokmanya Tilak Municipal Medical College, Mumbai, Maharashtra, India
Correspondence Dr. Siddharth Parekh Lokmanya Tilak Municipal Medical College, Mumbai, Maharashtra, India

\section{Functional outcome of posterior laminectomy in case of cervical myelopathy with multilevel cervical cord compression}

\author{
Dr. Siddharth D Parekh, Dr. Arvind B Goregaonkar, Dr. Anoop \\ Dhamangaokar, Dr. Apratim R Deekshit and Dr. Umesh P Kanade
}

DOI: https://doi.org/10.22271/ortho.2018.v4.i4f.56

\section{Abstract}

Objective: The primary objective is to study the functional outcome of cervical laminectomy with or without instrumentation for cervical myelopathy in case of multilevel cervical cord compression using modified JOA and NURICK score.

Introduction: Cervical myelopathy is a neurological pathology associated with a degenerative disease of the cervical spine resulting from a spinal cord compression. Cervical myelopathy presents with clinical implications in the upper and/or lower limbs caused by compression of the spinal cord. Loss of coordination, weakness and tactile sensitivity are some of the most common symptoms. Several procedures are available for the operative management of multi-level cervical spondylosis myelopathy or radiculopathy. Laminectomy has proven to be successful, but several inherent risks have been recognized. Postoperative instability and deformity, in particular kyphosis, is a well-documented problem.

Methodology: A prospective and retrospective cohort of 30 patients with cervical myelopathy with multilevel cord compression treated with posterior laminectomy between January 2016 to December 2017 were analysed for minimum of 1 year and final result were analysed with modified JOA and NURICK score.

Results: Cervical laminectomy as posterior approach alone or with posterior stabilisation with fusion can be chosen in patients of cervical myelopathy with multilevel cervical cord compression to achieve adequate decompression with comparable functional outcome as ACDF or ACCF.

Keywords: Laminectomy, cervical myelopathy, multilevel cervical cord compression, fusion, deformity

\section{Introduction}

Cervical myelopathy is a neurological pathology associated with a degenerative disease of the cervical spine resulting from a spinal cord compression. Calcification of the posterior longitudinal ligament, progressive cervical deformity, disc herniation, and trauma are the most common causes. Cervical myelopathy presents with clinical implications in the upper and/or lower limbs caused by compression of the spinal cord. Loss of coordination, weakness and tactile sensitivity are some of the most common symptoms. The patient with myelopathy may present with tremors and the loss of fine hand movements, difficulty in gripping objects, such as buttons, or manipulating a hook fastener. The patient and/or their family observe changes in walking, such as a progressive limp or difficulty in maintaining the swing phase. In more advanced cases, urinary urgency, hesitancy, and even retention of urine may occur. Several procedures are available for the operative management of multi-level cervical spondylotic myelopathy or radiculopathy. Laminectomy has proven to be successful, but several inherent risks have been recognized. Postoperative instability and deformity, in particular kyphosis, is a well-documented problem. Development of postoperative hematoma and peridural scar formation has also been documented. Expansive open-door laminoplasty, introduced by Hirabayashi in 1977. Decompresses the spinal cord with two theoretical advantages: 1) preservation of some posterior elements minimizes the possibility of postoperative instability or deformity while expanding the room available for the cord; 2) it may limit the formation of hematoma and postoperative membranes. 
The aim in this study was to evaluate the outcome in cases with multilevel cervical cord compression treated with posterior laminectomy.in patients with multilevel cervical cord compression in degenerative and indicative post traumatic cases. Conventionally, multilevel anterior cervical cord compression cases can be dealt with anterior multilevel discectomy and fusion (ACDF) or Corpectomy and fusion (ACCF). We proposed to study the functional outcome of posterior laminectomy in such cases.

\section{Methodology}

a. Design: Single centre, retrospective and prospective

b. Place of study: Our tertiary care centre

c. Proposed duration of study: 1 year

d. Sampling size: 30 (approximately)

e. Sampling method: In this study, all the patients presenting to our tertiary care centre with multilevel cervical cord compression and in whom surgical intervention is planned as cervical laminectomy with or without instrumentation.

f. Inclusion Criteria: All adult patients with degenerative and post traumatic multilevel cervical disc prolapsed with neuro deficit with MRI proven multilevel cervical cord compression at sub axial (C3-C7) who underwent posterior laminectomy with or without instrumentation.

g. Exclusion criteria: Patients, otherwise meeting the inclusion criteria, were ineligible in case of any of the following criteria:

1. Patients operated for other levels of spine involvement except multilevel

2. Cervical cord compression.

3. Patients been previously operated for cervical spine.

4. Cervical cord compression between occipitocervical, and C1-C2 Level.

5. Single level cervical cord compression.

6. Cervical cord compression with significant vertebral body injury/affection.

7. Patients having contraindication for Radiologica Assesment. e.g Pregnancy Paediatric patients and patients unfit for surgery with unstable vitals.

Patients fulfilling all inclusion and exclusion criteria were explained about the study and invited to participate in the study and an informed consent was taken. Patients were explained about procedure and about the need for follow up immediate post operatively, in between at periodic intervals and at the end of one year.

h. Parameters to be studied

1) Preoperative and Postoperative Neurology.

2) Level of cervical cord compression.

3) Functional outcome; JOA Score, NURICK'S Score.

4) Intraoperative- level of laminectomy

5) Radiological assessment-maintenance of cervical lordosis

i. Organisation of work elements: This study was undertaken after Ethical Committee clearance and was completed according to the fulfilment of closure criteria of the study. j. Work already done in the field:

1) Lacunae in subject knowledge: The primary objective was to study the functional outcome of cervical laminectomy with or without instrumentation for multilevel cervical cord compression.

\section{Proposed outcome of the project}

1. Improvement in patient care: YES

2. Attainment of more knowledge: YES

3. Bridging the lacunae in the knowledge: YES

\section{Observation and analysis}

30 patients with cervical myelopathy with multilevel cervical cord compression treated with posterior laminectomy were included in the study.

Table 1: Demographic Details of the All Patients Enrolled in the Study

\begin{tabular}{|c|c|}
\hline Total Number of Patients & 30 \\
\hline Gender Distribution & 24 Males (80\%),6 Males (20\%) \\
\hline $\begin{array}{c}\text { Mean age of the Patients Enrolled } \\
\text { (mean + SD) }\end{array}$ & $59.13+10.24$ years \\
\hline Minimum Age of Patient & 44 years \\
\hline Maximum Age of Patient & 78 years \\
\hline
\end{tabular}

Table 2: Mean Power in Upper and Lower Limbs after Cervical Laminectomy

\begin{tabular}{|c|c|c|c|c|c|}
\hline & \multirow{2}{*}{$\begin{array}{c}\text { Pre- } \\
\text { operative }\end{array}$} & \multicolumn{4}{|c|}{ Post-operative Assessment } \\
\hline & & 1 month & 3 months & 6 months & 1 year \\
\hline $\begin{array}{l}\text { Right Upper } \\
\text { Limb }\end{array}$ & $2.42+0.63$ & $\begin{array}{c}2.92+ \\
0.63\end{array}$ & $3.42+0.5$ & $3.42+0.5$ & $\begin{array}{c}3.71+ \\
0.53\end{array}$ \\
\hline $\begin{array}{l}\text { Left Upper } \\
\text { Limb }\end{array}$ & 2.4 & $\begin{array}{c}2.5+ \\
0.64 \\
\end{array}$ & $\begin{array}{c}3.03+ \\
0.33\end{array}$ & $\begin{array}{c}3.46+ \\
0.51\end{array}$ & $\begin{array}{c}3.67+ \\
0.47\end{array}$ \\
\hline $\begin{array}{c}\text { Right Lower } \\
\text { Limb }\end{array}$ & $3.07+0.53$ & $\begin{array}{l}3.08+ \\
0.55\end{array}$ & $\begin{array}{c}3.42+ \\
0.57\end{array}$ & $\begin{array}{c}3.64+ \\
0.55\end{array}$ & $\begin{array}{c}3.75+ \\
0.51\end{array}$ \\
\hline $\begin{array}{l}\text { Left Lower } \\
\text { Limb }\end{array}$ & $3.06+0.54$ & $\begin{array}{c}3.07+ \\
0.54\end{array}$ & $\begin{array}{c}3.43+ \\
0.58\end{array}$ & $\begin{array}{c}3.68+ \\
0.61\end{array}$ & $\begin{array}{c}3.78+ \\
0.57\end{array}$ \\
\hline
\end{tabular}

Table 2: Decrease in Sensations of patients after Cervical Laminectomy

\begin{tabular}{|c|c|c|c|c|}
\hline \multirow{2}{*}{ On Presentation } & \multicolumn{4}{|c|}{ Post-operative Assessment } \\
\cline { 2 - 5 } & 1 month & 3 months & 6 months & 1 year \\
\hline $32+6.32$ & $32+6.32$ & $24+6.99$ & $22+7.88$ & $17+6.75$ \\
\hline
\end{tabular}

Table 3: Bowel / Bladder function after Cervical Laminectomy

\begin{tabular}{|c|c|c|c|c|}
\hline \multirow{2}{*}{ On Presentation } & \multicolumn{4}{|c|}{ Post-operative Assessment } \\
\cline { 2 - 5 } & 1 month & 3 months & 6 months & 1 year \\
\hline $0.57+0.79$ & $0.57+0.79$ & $0.43+0.69$ & $0.32+0.55$ & $0.28+0.46$ \\
\hline
\end{tabular}

Table 4: The JOA Score after Cervical Laminectomy

\begin{tabular}{|c|c|c|c|c|}
\hline \multirow{2}{*}{ Pre-operative } & \multicolumn{4}{|c|}{ Post-operative Assessment } \\
\cline { 2 - 5 } & 1 month & 3 months & 6 months & 1 year \\
\hline $9.42+0.99$ & $9.82+0.86$ & $10.67+0.67$ & $11.5+0.96$ & $12.46+1.07$ \\
\hline
\end{tabular}

Table 5: Nurick Score after Cervical Laminectomy

\begin{tabular}{|c|c|c|c|c|}
\hline \multirow{2}{*}{ Pre-operative } & \multicolumn{4}{|c|}{ Post-operative Assessment } \\
\cline { 2 - 5 } & 1 month & 3 months & 6 months & 1 year \\
\hline $3.78+0.42$ & $3.75+0.44$ & $3.25+0.44$ & $3+0.47$ & $2.71+0.46$ \\
\hline
\end{tabular}



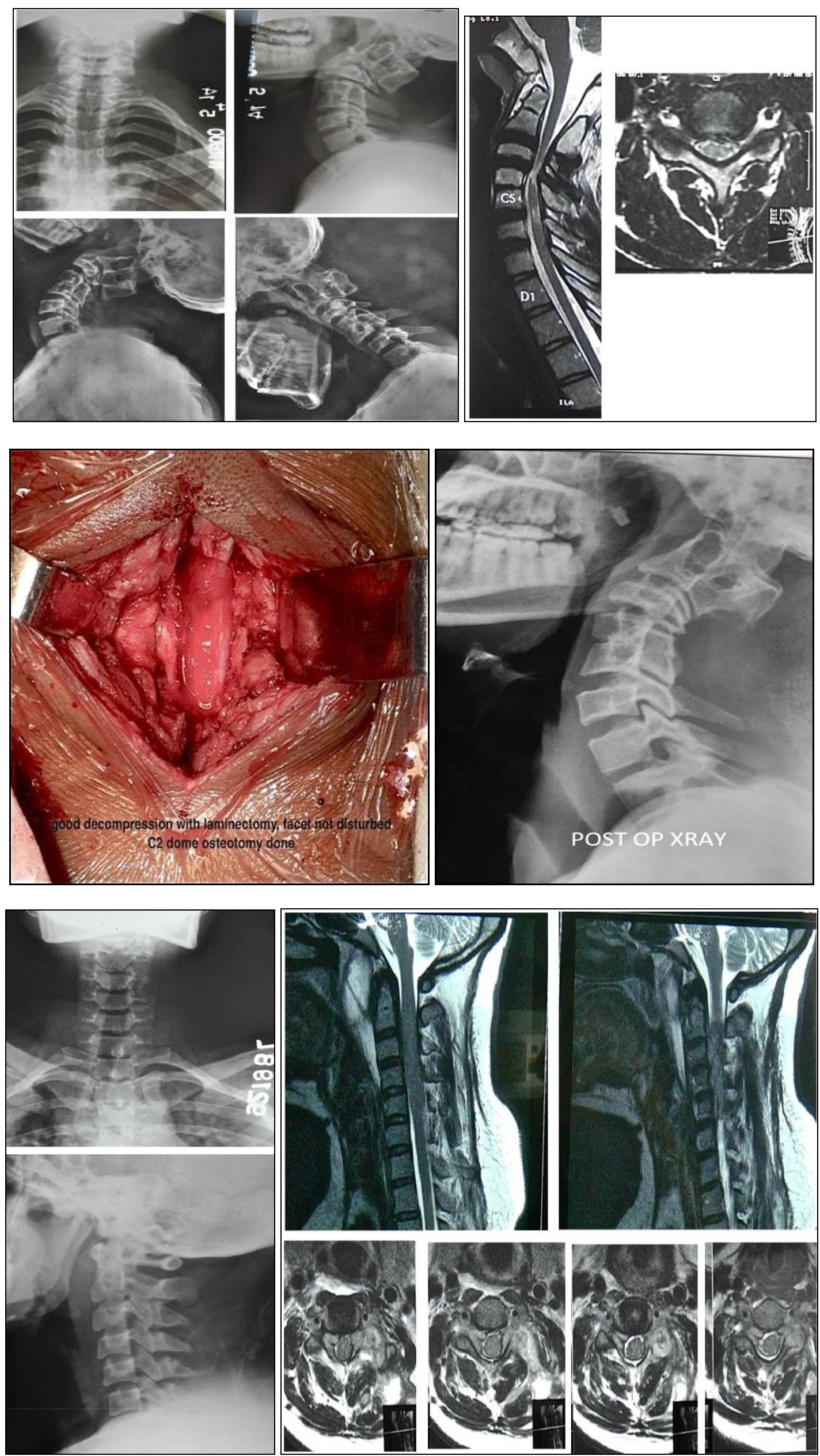

Case 1: Only Laminectomy 

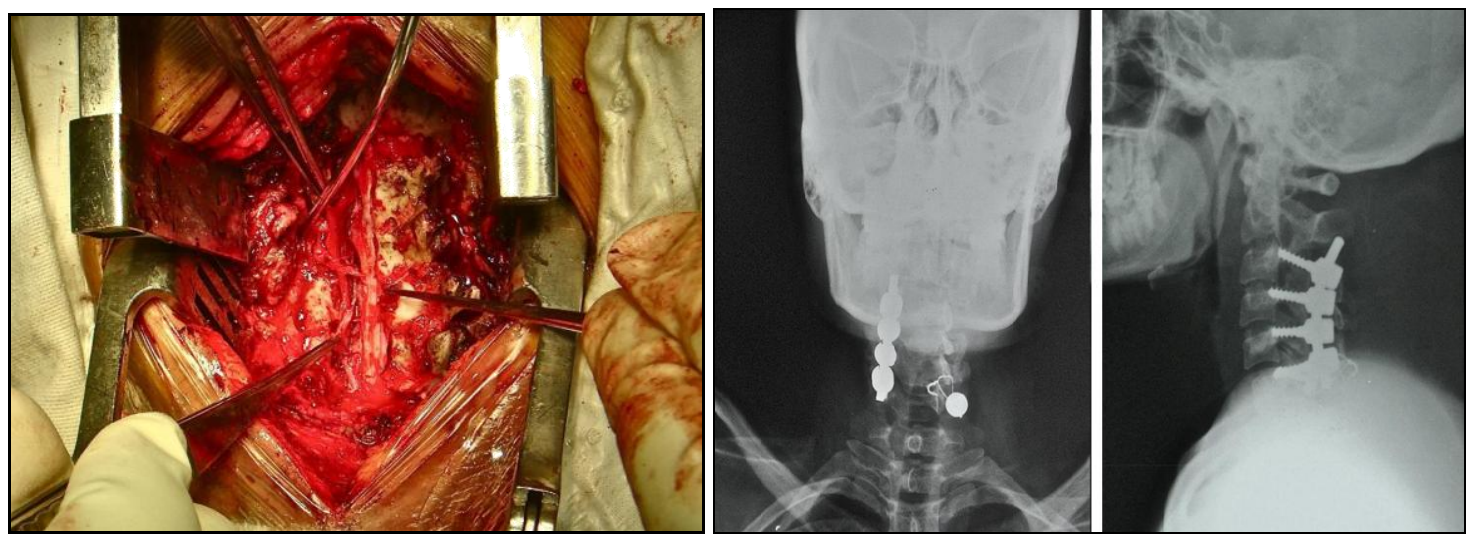

Case 2: Laminectomy and Fusion

\section{Discussion}

Cervical laminectomy remains a useful operative alternative for management of cervical spondylotic myelopathy where the lordotic curve well preserved. This is particularly true in geriatric age group where co-morbidities increases operative risk, cervical laminectomy address congenital or acquired stenosis, multilevel spondylosis, OPLL, OYL, chronic olisthy or frank instability may be selectively and simultaneously addressed with varying way of posterior stabilisation procedure.

The patient were followed for a minimum 12 months out of which 24 patient were Male \& 6 patients were female. The age of cases ranging from 44 to 78 years with

SD 10.24yrs mean age 59.13yrs. The groups were comparable in case of Compression, level of compression, level of laminectomy in cases of multilevel

Cervical spondylosis myelopathy.

The level of compression included in our study from $\mathrm{C} 2-\mathrm{C} 7$. The patient having $\mathrm{C} 4-\mathrm{C} 6$ is $9, \mathrm{C} 3-\mathrm{C} 5$ is $6, \mathrm{C} 5-\mathrm{C} 7$ is $5, \mathrm{C} 2-\mathrm{C} 4$ is 4 , and C3-C6 is 3. C2-C4-C5 is 2 \& $\mathrm{C} 4-\mathrm{C} 5$ is

The entrap level of laminectomy of patient included on study is found as $\mathrm{C} 4-\mathrm{C} 7$ is $8, \mathrm{C} 3-\mathrm{C} 6$ is $6, \mathrm{C} 2-\mathrm{C} 6$ is $5, \mathrm{C} 2-\mathrm{C} 5$ is 5 , $\mathrm{C} 3-\mathrm{C} 7$ is 4 , and $\mathrm{C} 2-\mathrm{C} 7$ is 2 as multilevel compression

Have to decompress 1 level up \& 1 level down to prevent/delay relapse better outcome.

Patient were given JOA and Nurick score preoperatively based on their Sensory, motor, reflex \& bladder bond involvement. Motor function is described as

Power for convenience shoulder, elbow, and wrist \& hand grip combined expressed as

Upper limb \& Hip, knee, ankle \& EHL/FHL combined expressed as lower limb overall

Power that is measured in right $\&$ left side. Patients were examined preop, post op at 1 month, 3 month, 6 month \& 12 month interval.

According to this data, improvement in power in upper limb \& lower limb in both right \& left side Is statistically significant over a period of 12 months a Compared to pre op status. Mean Upper limb power pre op is $2.42(\mathrm{R}), 2.46(\mathrm{~L})$ side.

Mean lower limb power preop is $3.07(\mathrm{R})$ \& 3.06(L) side. Improvement in right side

Compared to left side is statistically non-significant. Change is more on Right side but that is statistically non-significant. For upper limb power at 1 month on

Right side is 2.92 \& on left side is 2.5 which is significant. At 3 months it is 3.42 in right side \& 3.03 on left side which is significant. At 6 months it is 3.42 on the right side \& 3.46 on the left side which is significant. At 12 month it is 3.71 on the right side \& 3.67 on the left side which is significant. For lower limb, power at 1 month is 3.08 on the right side \& 3.07 on the left side which Is significant. At 3 months it is 3.42 on right side $\& 3.43$ on the left side which is significant. At 6 months it is 3.64 on the right side \& 3.68 on the left side which is significant. At 12 months it is 3.75 on the right side $\& 3.78$ on the left side which is significant.

10 Patient has sensory loss at the pre op stage that has improved over a period of 12 months. Average sensory loss has decreased from $32 \%$ loss to $17 \%$ loss at 12 months that is statistically significant.

No patient has superficial reflex present at the preop stage that has improved over a period of 12 months. At 1 month it is 0 , at 3 months it is 1 , at 6 months it is $14 \&$ at 1 year it is 18 that is statistically significant improvement of decompression of cord.

11 Patients had urinary bladder involvement at the time of presentation grading from severe, mild \& normal improved gradually over a period of 12 months.

Score improved from 0.57 preop to 0.28 at 12 months post op that is statistically Significant at 1, 3 and 6 months also.

Out of 30 patients, 5 patients $(\sim 17 \%)$ preop maintained cervical lordosis.

In post op patients $24(80 \%)$ maintained cervical lordosis. Out of 24 patients who maintained cervical post op lordosis, 15 patient are with laminectomy \&

Stabilisation, 5 with Preop maintained cervical lordosis. 15 patients with only Laminectomy, 6 patient not maintained lordosis which is $40 \%$ at 1 year which is Significant. Suggest that loss of cervical lordosis in patients treated with only multilevel laminectomy is consistent and known condition that does not affects the functional improvement. JOA score clinical grade of improvement improved from preop 9.42 to post op 12.46 over period of 12 months with improvement at given period of examination That is statistically significant at $1,3 \& 6$ months. At pre op 4 patient in grade 3

Decreased to 0 in grade 3 after 1 year. 26 patient in grade 2 improved to 5 patients in

Grade $2 \& 23$ patients came in grade 1 .

Nurick score, based on gait and ambulatory function, grade of improvement, improved from 3.78 preop score to 2.71 post op score over a period of 12 months that is statistically significant at 1, 3 and 6 months, with significant improvement at given time period.

It is clear from these patient group with cervical laminectomy alone or laminectomy with posterior stabilisation in the form of $\mathrm{k}$ wire or lateral mass screw.

The fear that only laminectomy for multilevel cord compression may lead to instability which interfere with functional improvement us largely dispelled. One shortcoming of this study is the small number of patients with 
particular disease types in group. There were no consistent complications or outcome differences related to specific approach. Long term study for continuation of improvement of symptoms till which period and late onset detoriation and progression of disease should be undertaken.

\section{Conclusion}

Cervical laminectomy as posterior approach alone or with posterior stabilisation with fusion can be chosen in patients of cervical myelopathy with multilevel cervical cord compression to achieve adequate decompression with comparable functional outcome as ACDF or ACCF. Thus decision may be based on surgeon preference and specific condition and indications of the patient but the cervical laminectomy also give the favourable and comparable outcome.

\section{References}

1. Fager C. Results of adequate posterior decompression in the relief of spondylotic cervical myelopathy. Journal of Neurosurgery. 1973; 38(6):684-692.

2. Gorter K. Influence of laminectomy on the course of cervical myelopathy. Acta Neurochirurgica. 1976; 33(34):265-281.

3. González-Feria L, Peraita-Peraita P. Cervical spondylotic myelopathy: A cooperative study. Clinical Neurology and Neurosurgery. 1975; 78(1):19-33.

4. Casotto A, Buoncristiani P. Posterior approach in cervical spondylotic myeloradiculopathy. Acta Neurochirurgica. 1981; 57(3-4):275-285.

5. Epstein J, Janin Y, Carras R, Lavine L. A comparative study of the treatment of cervical spondylotic Myeloradiculopathy. Acta Neurochirurgica. 1982; 61(13):89-104.

6. Epstein N. Laminectomy with Posterior Wiring and Fusion for Cervical Ossification of the Posterior Longitudinal Ligament, Spondylosis, Ossification of the Yellow Ligament, Stenosis, and Instability. Journal of Spinal Disorders. 1999; 12(6):461466.

7. Yonenobu K, Fuji T, Ono K, Okada K, Yamamoto T, Harada N. Choice of surgical treatment for Multisegment cervical spondylotic myelopathy. Spine. 1985; 10(8):710716.

8. Miyazaki K, Tada K, Matsuda Y, Okuno M, Yasuda T, Murakami H. Posterior extensive simultaneous Multisegment decompression with posterolateral fusion for cervical myelopathy with cervical instability and kyphotic and/or s-shaped deformities. Spine. 1989; 14(11):1160-1170.

9. Miyazaki K, Kirita Y. Extensive Simultaneous Multisegment Laminectomy for Myelopathy Due to the Ossification of the Posterior Longitudinal Ligament in the Cervical Region. Spine. 1986; 11(6):531-542.

10. Mikawa Y, Shikata J, Yamamuro T. Spinal Deformity and Instability after Multilevel Cervical Laminectomy. Spine. 1987; 12(1):6-11.

11. Arnasson O, Carlsson C, Pellettieri L. Surgical and conservative treatment of cervical spondylotic radiculopathy and myelopathy. Acta Neurochirurgica. 1987; 84(1-2):48-53. 